\section{Gategory}

Synthesis of Natural Products and

Potential Drugs

\section{Key words}

\section{atorvastatin}

enantioselectivity

oxa-Michael

reaction

organocatalysis

Y. KOBAYASHI, Y. TANIGUCHI, N. HAYAMA, T. INOKUMA, Y. TAKEMOTO* (KYOTO UNIVERSITY, JAPAN)

A Powerful Hydrogen-Bond-Donating Organocatalyst for the Enantioselective Intramolecular Oxa-Michael Reaction of $\alpha, \beta$-Unsaturated Amides and Esters

Angew. Chem. Int. Ed. 2013, 52, 11114-11118.

\title{
A Formal Synthesis of Atorvastatin
}
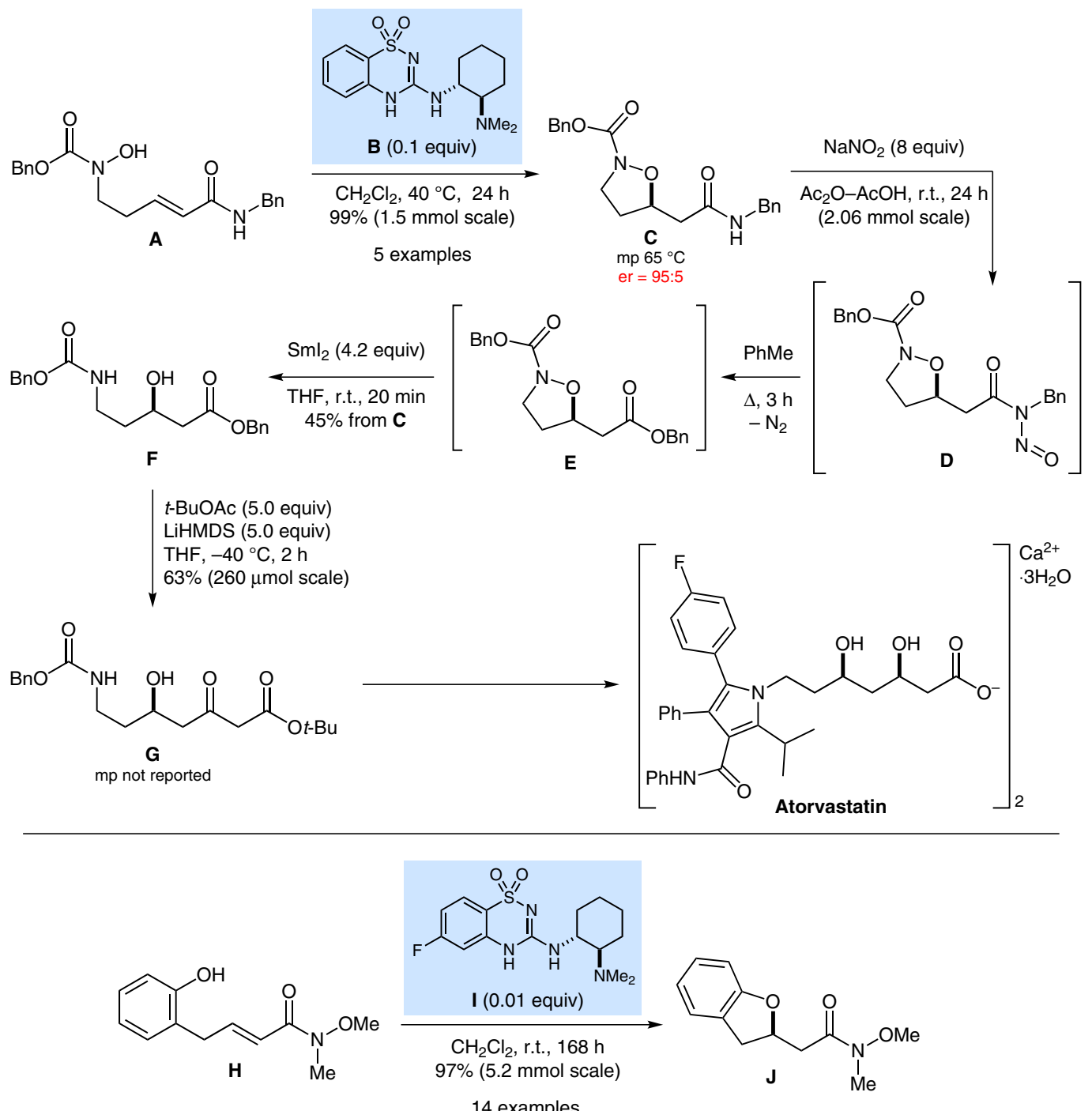

Significance: The key step in this formal synthesis of atorvastatin $\left(\right.$ Lipitor $\left.^{\circledR}\right)$ is the enantioselective intramolecular oxa-Michael reaction of $\mathbf{A}$ mediated by 10 mol\% of benzothiadiazine catalyst B. Methods for converting $\mathbf{G}$ and its relatives into atorvastatin have been summarized by $Y$. Kawato et al. (Chem. Eur. J. 2013, 19, 3802; see also references therein).

SYNFACTS Contributors: Philip Kocienski

Synfacts 2014, 10(1), 0006 Published online: 13.12.2013

DOI: 10.1055/s-0033-1340325; Reg-No.: K07113SF
Comment: For the conversion of $\mathrm{N}$-nitrosamides into esters (e.g., D $\rightarrow$ E), see: D. T. Glatzhofer, R. R. Roy, K. N. Cossey Org. Lett. 2002, 4, 2349. Phenolic nucleophiles (14 examples) also participate in the oxa-Michael reaction, and in the case of $\mathbf{H}$ only $1 \mathbf{m o l} \%$ of catalyst $\mathbf{I}$ is required. 